\title{
Comparative Radiopacity of Pediatric Dental Restorative Materials
}

\begin{abstract}
SUMMARY
Background/Aim: Radiopacity of dental restorative materials is significant to detect secondary caries, overhangs, and voids. This study aimed to evaluate whether radiopacity of dental restorative materials used in pediatric dentistry was sufficient. Material and Methods: Specimens of $2 \mathrm{~mm}$ thickness and $4 \mathrm{~mm}$ diameter were prepared in the plastic molds. Six composite materials, one compomer material, and one conventional glass ionomer cement were used and three specimens of each material were prepared. Three radiographs were taken from dental restorative materials and aluminum step wedge. Digital images obtained were recorded. Mean gray values of the dental restorative materials and aluminum step wedge were measured on digital radiographs. Results: All composite resins displayed higher radiopacity values than an equal thickness of $2 \mathrm{~mm} \mathrm{Al}$. Posterior composite (201.62 \pm 1.99 MGV) showed higher radiopacity value than the anterior composite $(86.19 \pm 1.45 \mathrm{MGV})$. There was no significant difference in radiopacity values of different shades of the same composite. There was no significant difference in radiopacity values between glass ionomer cement and compomer. Glass ionomer cement showed higher radiopacity value $(8.11 \mathrm{~mm} \mathrm{Al})$ than anterior composite $(5.31 \mathrm{~mm} \mathrm{Al})$. Conclusions: Radiopacity values of dental materials used in this study were sufficient. Both resin materials and the glass ionomer cement had sufficient radiopacity values. Posterior composite showed the highest radiopacity value. Radiopacity values were not affected by different shades.
\end{abstract}

Key words: Radio-Opacity, Resin Composite, Digital Radiography, Restorative Material

\author{
Berna Kuter, Ilhan Uzel \\ 1 Department of Paediatric Dentistry, Faculty \\ of Dentistry, Izmir Demokrasi University, \\ Guzelyali, Izmir, Turkey \\ 2 Department of Paediatric Dentistry, Faculty \\ of Dentistry, Ege University, Bornova, Izmir, \\ Turkey
}

ORIGINAL PAPER (OP)

Balk J Dent Med, 2022;47-51

\section{Introduction}

The advantage of radiopaque dental materials is the detection of secondary dental caries ${ }^{1}$. Many studies have been reported on obtaining optimal radiopacity for dental materials ${ }^{2}$. It was stated that radiopacity of dental material should be equal to or higher than the same thickness of aluminum $^{3}$. It is easy to realize voids and overhangs, detect open margins ${ }^{4}$, provide proper contacts when dental materials include radiopaque materials ${ }^{5}$. It has also been reported that secondary caries mostly appears on the proximal gingival region, it is difficult to diagnose and the most common reason for replacement of dental restorations ${ }^{6}$.
Glass ionomer cement was reported to have low radiopacity ${ }^{7}$. Low radiopacity of first glass ionomer cements produced limited their use. Besides, only some of the composite materials tested met the criteria for radiopacity, while a few materials did not ${ }^{8}$. Furthermore, the same results have been reported for flowable composites $^{4}$. However, practitioners prefer to use dental restorative materials with high radiopacity.

Radiography is a primary diagnostic tool of the dentist and the only way to identify secondary dental caries in the patients examined ${ }^{9}$. Radiographic images can be stored in digital systems and this technique needs fewer radiation dosages. Digital radiographic systems 
have greater sensitivity of determination compared to the traditional system ${ }^{10}$. Also, radiation dose is decreased as the exposure time reduces. Digital radiographic images can be manipulated digitally for contrast, enlargement, adjustment, and density ${ }^{11}$. Furthermore, quantitative measurements and special effects can be used. Number of gray shades is shown by bits called a pixel. Gray value can be from 8 to16 bits. Digital radiographic technique is reliable, speedy, basic, and precise way to examine different restorative materials ${ }^{8}$.

The purpose of this study was to evaluate the radiopacity of dental restorative materials used in pediatric dentistry by using digital image analysis technique to establish the mean gray values and to determine whether their radiopacity is sufficient.

\section{Material and Methods}

\section{Materials}

Eight different materials were used in this study: six composite materials, one compomer material, and one conventional glass ionomer cement (Table 1). Three samples of each material were prepared. Among others, three flowable composites were included in this study. One of them was supra-nano hybrid, second was nanohybrid and the third was submicron-filled flowable composite. Anterior, posterior version and two shade of a composite were evaluated.

\section{Specimen preparation}

Disc-formed specimens of $2 \mathrm{~mm}$ thickness and $4 \mathrm{~mm}$ diameter were prepared in the plastic molds. Each restorative material was mixed according to the manufacturers' instructions. The molds were wrapped with a strip to get a smooth surface. The other strip and plate were placed on top of the specimen to provide a smooth surface. Resin composite was polymerized with a light-emitting diode curing lamp (Bluephase, Ivoclar Vivadent) according to the manufacturer's instructions. Conventional glass ionomer samples were taken out from the mold according to the manufacturer's instructions. All the samples were controlled and changed with other samples when they were not homogeneous. The specimens were kept in distilled water and measurements were performed after $24 \mathrm{~h}$ to allow the polymerization of the dental materials to complete.

Table 1. Materials used in the study

\begin{tabular}{llll}
\hline Brand name & \multicolumn{1}{c}{ Type } & Shade & \multicolumn{1}{c}{ Manufacturer } \\
\hline Ketac Molar & Conventional restorative glass ionomer cement & A1 & 3M ESPE, Germany \\
Glasiosite & Light curing compomer & A1 & Voco-GmbH-Voco-Dental, Germany \\
Estelite $\Sigma$ Quick & Supra-nano filled composite resin & A1 & Tokuyama Dental Corporation, Japan \\
G-ænial anterior & Hybrid composite & A1 & GC, USA \\
$\begin{array}{l}\text { Meta Biomed } \\
\text { Nexcomp }\end{array}$ & Nano-Hybrid Flowable Composite Resin & A1 & META BIOMED, USA \\
G-ænial posterior & Hybrid composite & A1 & GC, USA \\
Estelite Flow Quick & Submicron filled composite resin & A1 & Tokuyama Dental Corporation, Japan \\
& & A2 & GC, USA \\
G-ænial posterior & Hybrid composite & & \\
\hline
\end{tabular}

\section{Radiographic Procedure}

The sets of restorative material specimens were radiographed with an aluminum step wedge (aluminumalloy- $99.5 \%$ of $\mathrm{Al}$ ), utilized as a pattern ${ }^{12}$. Step wedge had ten steps, with a thickness of 1.00, to $10.00 \mathrm{~mm}^{13}$. Radiographic displays were obtained with a phosphor plate system (Digora Imaging Plate, Soredex Corporation, Finland) and a digital X-ray device
(Planmeca Prostyle Intra, Helsinki, Finland) adjusting at $70 \mathrm{kV}$ and $10 \mathrm{~mA}$ with a total filtration equivalent of $2.0 \mathrm{~mm}$ of $\mathrm{Al}^{14}$. The exposure time was $0.25 \mathrm{sec}$ and focal point to sample distance was $40 \mathrm{~cm}^{14}$. A 2- mm thick lead sheet plate was used under the samples to avoid back scattered radiation ${ }^{15}$. Three radiographs were taken from dental restorative materials. The digital images obtained were recorded in the TIFF format. 


\section{Radiopacity measurements}

Radiopacity measurements of 50x50 pixel areas taken from three different regions of each sample were evaluated. Each sample was submitted to an exposure. Radiopacity values were converted into millimeters of aluminum $(\mathrm{mm} \mathrm{Al})$, that presented the same radiopacity of each material, according to Vivan et al. ${ }^{16}$.

Mean gray values of the samples (MGVs) were measured on digital radiographs using a Java-based image processing program developed at the National Institutes of Health and the Laboratory for Optical and Computational Instrumentation (National Institutes of Health, Maryland, $\mathrm{ABD})$. Measurements were done by an operator.

\section{Data Analysis}

It was analyzed by Mann-Whitney U Test to compare the radiopacity values of dental materials and Two Independent Samples Test was used to compare materials. The $\mathrm{mm} \mathrm{Al}$ of restorative materials was measured, and $p$ was set as $<0.05$.

\section{Results}

The MGV and mean radiopacity reported as $\mathrm{mm} \mathrm{Al}$ of the restorative dental materials were shown in Table 2. There was a significant difference in the radiopacity values of the different restorative materials. All composite resins displayed higher radiopacity values than an equal thickness of $2 \mathrm{~mm}$ Al. Posterior version of composite showed higher radiopacity value (MGV) than anterior version of composite. There was no significant difference in the radiopacity values (MGV) of different shades of the same composite $(p>0.05)$. There was no significant difference in the radiopacity values (MGV) between the glass ionomer cement and the compomer ( $p>$ $0.05)$. There was no significant difference in the radiopacity values (MGV) between flowable composite resin and compomer ( $\mathrm{p}>0.05)$.

Table 2. MGV and radiopacity of the dental materials, estimated for the samples of $2 \mathrm{~mm}$ thickness. The values are shown as mean \pm standard deviation

\begin{tabular}{lcc}
\hline Material & MGV & $\begin{array}{c}\text { Radiopacity } \\
(\mathrm{mmAl})\end{array}$ \\
\hline Ketac Molar & $148.36 \pm 3.40$ & 8.1199 \\
Glasiosite & $174.90 \pm 2.09$ & 9.1259 \\
Estelite $\Sigma$ Quick & $108.98 \pm 2.05$ & 5.9365 \\
G-ænial anterior & $86.19 \pm 1.45$ & 5.3176 \\
Meta Biomed Nexcomp & $130.51 \pm 5.08$ & 7.2270 \\
G-ænial posterior (Shade A1) & $191.20 \pm 2.15$ & 10.6892 \\
Estelite Flow Quick & $119.00 \pm 2.61$ & 7.0068 \\
G-ænial posterior (Shade A2) & $201.62 \pm 1.99$ & 10.9472 \\
\hline
\end{tabular}

\section{Discussion}

Different studies have reported different radiopacity values of the same dental materials ${ }^{13}$, since the variations of exposure time, the voltage of digital radiographic units, containing aluminum step wedge could affect the radiopacity values. Also, material composition affects the radiopacity values ${ }^{14}$. Resin percentage and filler type influence the radiopacity of resin composites ${ }^{4,17}$. Elements with high atomic numbers provide higher radiopacity of dental materials than the elements with low atomic numbers ${ }^{17}$. It was preferred that dental materials have high radiopacity, however, it was reported that radiopaque dental materials disrupt the visual acuity and particulars ${ }^{1}$. As it could cause radiographic misdiagnosis ${ }^{18}$, the moderate radiopacity should be more appropriate, as it was reported ${ }^{1}$.

Human tooth structure could be a better reference for opacities of dental materials, however, different studies showed different results for tooth structure ${ }^{19}$. Therefore, aluminum step wedge was used for measurements of the radiopacity values of dental restorative materials in this study.

Sabbagh et al., reported that despite numerous advantages of digital imaging systems ${ }^{11},{ }^{17}$, the conventional radiographic imaging system was more accurate for radiopacity measurements ${ }^{16}$. Furthermore, it was reported that it is sufficient to convert the pixel values to equivalent millimeters of aluminum. Besides, digital radiography systems generally showed the lowest radiopacity variability of the methodologies compared with the photo densitometer used in conventional radiograph $s^{20}$. The radiographic images with digital systems were not influenced by exposure time due to the broad latitude of the phosphor plate. It is important for the standardization of radiopacity values of dental materials in digital imaging techniques.

It is important to select the appropriate material to distinguish secondary caries, voids, overhangs and open margins especially in the posterior regions ${ }^{4}$. Hitij and Fidler have reported that although most of the dental materials had sufficient radiopacity in diagnosis of secondary caries, manufacturers' information was not trust worthy, at all times ${ }^{9}$. Both Sabbagh et al., ${ }^{17}$ and Ergucu et al. ${ }^{14}$, reported that some of the radiopacities of flowable composites were not sufficient. Tsuge et al., revealed that the radiopacity value of resin-based materials was sufficient, however, it was slightly higher than enamel ${ }^{2}$. Both Prevost et al. and Hara et al., showed that the glass-ionomer cements had lower and insufficient radiopacity values than those of the other dental materials ${ }^{21,22}$. Prevost et al., stated that the restorative glass ionomer cement had lower radiopacity than dentin in that study ${ }^{21}$. Hara et al., reported that all hybrid materials had more radiopacity than conventional glass ionomer ${ }^{22}$. Pekkan et al., reported that the glass- 
ionomer cements should be used carefully because of the lowest radiopacity values among all dental materials ${ }^{23}$. While glass-ionomer cement had a lower radiopacity value than aluminum, the composite resins had higher radiopacity than it was declared in the other study ${ }^{19}$.

In this study, fluoroaluminosilicate glass was added to the posterior formulation for increased radiopacity, and silica was used in the anterior formulation as reported by the manufacturer. Aluminosilicate glass makes glass ionomers radiolucent material ${ }^{21}$. Various radiopaque materials such as strontium and barium glass are preferred as powder components of glass ionomer cements ${ }^{24}$. Radiopacity of glass ionomer cement used in this study was sufficient and of high value. There was no significant difference in the radiopacity values between the glassionomer cement and the compomer.

Inorganic filler content determines the radiopacity of dental materials ${ }^{2,17}$. Materials exhibit higher radiopacity if it contains more filler. Radiopacity of three flowable composites used in this study (supra-nanohybrid, nanohybrid and submicron-filled flowable composite resin) was sufficient and showed radiopacity values of 5.93, 7.22 and $7.00 \mathrm{~mm} \mathrm{Al}$, respectively. Supra-nanohybrid flowable composite resin showed lower radiopacity value than the other flowable composite resins. Nano-hybrid flowable composite resin and submicron-filled flowable composite resin showed similar radiopacity values and these materials showed higher radiopacity values than the supra-nanohybrid flowable composite resin.

Two types of hybrid composites were used (anterior and posterior) in this study and two shades to assess if there were different radiopacity values between them. Posterior versions were found more radiopaque than anterior versions. Anterior version showed the lowest radiopacity value of all materials. The glass ionomer cement showed higher radiopacity value $(8.11 \mathrm{~mm} \mathrm{Al})$ than the anterior composite $(5.31 \mathrm{~mm} \mathrm{Al})$. Among the dental materials used in this study, the posterior composite showed higher radiopacity value than the others. Furthermore, there was no difference between two shades of the same composite resin.

\section{Conclusions}

It can be concluded that all dental restorative materials used in this study had sufficient radiopacity values. Conventional glass ionomer cement showed high radiopacity value. Posterior composite had the highest radiopacity value among all materials used. Radiopacity values were not affected by different shades. Conventional glass ionomer cement and the compomer showed similar radiopacity values.

\section{References}

1. Espelid I, Tveit AB, Erickson RL, Keck SC, Glasspoole EA. Radiopacity of restorations and detection of secondary caries. Dent Mater, 1991;7:114-117.

2. Tsuge T. Radiopacity of conventional, resin-modified glass ionomer, and resin-based luting materials. J Oral Sci, 2009;51:223-230.

3. ISO - ISO 4049:2009 - Dentistry — Polymer-based restorative materials. Accessed December 27, 2020. https:// www.iso.org/standard/42898.html

4. Nuray Attar, Tam LE, Mccomb D. Flow, Strength, Stiffness and Radiopacity of Flowable Resin Composites. J Can Dent Assoc, 2003;69:516-521.

5. Taira M, Toyooka H, Miyawaki H, Yamaki M. Studies on radiopaque composites containing $\mathrm{ZrO} 2 \mathrm{SiO} 2$ fillers prepared by the sol-gel process. Dent Mater, 1993;9:167-171.

6. Mjor IA. The Location of Clinically Diagnosed Secondary Caries. Quintessence Int, 1998;29:313-317.

7. Skartveit L, Halse A. Radiopacity of glass ionomer materials. J Oral Rehabil, 1996;23:1-4.

8. Dukic W, Delija B, Derossi D, Dadic I. Radiopacity of composite dental materials using a digital X-ray system. Dent Mater J, 2012;31:47-53.

9. Hitij T, Fidler A. Radiopacity of dental restorative materials. Clin Oral Investig, 2013;17:1167-1177.

10. Wenzel A, Gröndahl HG. Direct digital radiography in the dental office. Int Dent J, 1995;45:27-34.

11. Nomoto R, Mishima A, Kobayashi K, McCabe JF, Darvell BW, Watts DC, et al. Quantitative determination of radioopacity: Equivalence of digital and film X-ray systems. Dent Mater, 2008;24:141-147.

12. Kapila R, Matsuda Y, Araki K, Okano T, Nishikawa K, Sano T. Radiopacity Measurement of Restorative Resins Using Film and Three Digital Systems for Comparison with ISO 4049: International Standard. Bull Tokyo Dent Coll, 2015;56:207-214.

13. $\mathrm{Gu} \mathrm{S}$, Rasimick BJ, Deutsch AS, Musikant BL. Radiopacity of dental materials using a digital X-ray system. Dent Mater, 2006;22:765-770.

14. Ergücü Z, Türkün LS, Önem E, Güneri P. Comparative radiopacity of six flowable resin composites. Oper Dent, 2010;35:436-440.

15. Emin Kaval M, Akin H, Güneri P. Evaluation of the radiopacity of various post materials. Off Publ Cumhur Univ Fac Dent Cumhur Dent J, 16:2146-2852.

16. Vivan RR, Ordinola-Zapata R, Bramante CM, Bernardineli $\mathrm{N}$, Garcia RB, Duarte MAH, et al. Evaluation of the radiopacity of some commercial and experimental rootend filling materials. Oral Surg Oral Med Oral Pathol Oral Radiol Endod, 2009;108:e35-38.

17. Sabbagh J, Vreven J, Leloup G. Radiopacity of resinbased materials measured in film radiographs and storage phosphor plate (Digora). Oper Dent, 2004;29:677-684.

18. Imperiano MT, Khoury HJ, Pontual MLA, Montes MAJR, da Silveira MMF. Comparative radiopacity of four low-viscosity composites. Brazilian J Oral Sci, 2007;6:1278-1282.

19. Akerboom HBM, Kreulen CM, van Amerongen WE, Mol A. Radiopacity of posterior composite resins, composite resin luting cements, and glass ionomer lining cements. J Prosthet Dent, 1993;70:351-355. 
20. Ochoa-Rodríguez VM, Wilches-Visbal JH, Roma B, Coaguila-Llerena H, Tanomaru-Filho M, Andréa GonÇalves A, et al. Radiopacity of endodontic materials using two models for conversion to millimeters of aluminum. Braz Oral Res, 2020;34:e080.

21. Prévost AP, Forest D, Tanguay R, DeGrandmont P. Radiopacity of glass ionomer dental materials. Oral Surg Oral Med Oral Pathol, 1990;70:231-235.

22. Takeo Hara A, Campos Serra M, Luiz Rodrigues Jr A. Radiopacity of Restorative Materials. Braz Dent J, 2011;12:85-89.

23. Gürel Pekkan C, Pekkan G, Sarıdağ S, Çelebi Beriat N. Evaluation Of The Radiopacity Of Some Luting, Lining And Filling Dental Cements. Clin Dent Res, 2011;35:2-9.

24. Fonseca RB, Branco CA, Soares PV, et al. Radiodensity of base, liner and luting dental materials. Clin Oral Investig, 2006;10:114-118
Conflict of Interests: Nothing to declare.

Financial Disclosure Statement: Nothing to declare.

Human Rights Statement: None required.

Animal Rights Statement: None required.

Received on February 4, 2021.

Revised on April 12, 2021.

Accepted on September 2, 2021.

\section{Correspondence}

\section{Berna Kuter}

Department of Paediatric Dentistry, Faculty of Dentistry Izmir Demokrasi University, Guzelyali, Izmir, Turkey e-mail:berna.kuter@idu.edu.tr 